\title{
FORMULAÇÃO DE INDICADORES DE IMPACTO PARA MICROFINANÇAS
}

\author{
Tania P. Christopoulos \\ Universidade de São Paulo (USP) \\ Tomás C. A. Marques \\ Universidade de São Paulo (USP)
}

FORMULAÇÃO DE INDICADORES DE IMPACTO PARA MICROFINANÇAS

Resumo: Durante os últimos anos, têm sido investidos muitos recursos para promoção de políticas de inclusão financeira no Brasil, em especial de grupos marginalizados do sistema bancário tradicional. Torna-se portanto, fundamental, compreender qual é o impacto dessas políticas para o público beneficiado. Para tanto, o presente artigo tem como objetivo discutir e apresentar a aplicação de uma metodologia para desenvolvimento de indicadores e para avaliação do impacto de microfinanças, baseada no enfoque metodológico denominado botton-up. Esse enfoque reflete uma dinâmica participativa e propositiva no sentido de proporcionar o apoderamento dos atores envolvidos em todo o processo de formulação dos indicadores, e contempla, de forma geral, as especificidades existentes nas localidades que se pretende avaliar. A aplicação do estudo se deu através de pesquisa realizada com grupos envolvidos com ações e impactos das atividades de microfinanças e possibilitou a elaboração de um quadro de indicadores relevantes.

Palavras-chave: Microfinanças, bancos comunitários, indicadores, participativa, bottom-up

\section{THE DEVELOPMENT OF IMPACT INDICATORS FOR MICROFINANCE}

Abstract: During the last years, considerable resources have been invested in order to promote policies of financial inclusion in Brazil, especially to include the ones marginalized from the traditional banking system. Therefore, it is relevant to understand how to assess the impact of these policies on the target public benefited. For that, this article aims to discuss and present the application of a methodology to develop indicators and assessing the impact on microfinance policies, based on a methodological approach called bottom-up. This approach reflects a participatory and proactive process, empowering the actors involved in the process of formulating indicators, and considers, in a general way, the specific situation in the localities assessed. The study's application was conducted with groups involved with actions and impact of microfinance activities, and enabled the development of a framework of relevant indicators.

Key words: Microfinance, community banks, indicators, participatory, bottom-up. 


\section{INTRODUÇÃO}

Governos e organismos do terceiro setor utilizam as informações derivadas das mensurações propiciadas pelos indicadores como instrumento de planejamento, ou para suprir deficiências de análises estritamente econômicas (SANTAGADA, 1993). Decorre como resultado, a elaboração de um planejamento resultante dos indicadores, que não é neutro e sempre estará referido a um sistema de valores, que determinaram o quê e para quem planejar (COSTA, 1975). No mesmo sentido, Rattner (1977) aponta que o planejamento é essencialmente um ato político, o qual é baseado nos interesses dos diferentes grupos envolvidos. Contudo, o autor sugere que esses grupos de interesse sejam parte da formulação do planejamento e que, somente assim, será possível buscar alguma racionalidade (RATTNER, 1977).

Os indicadores podem, também, ser utilizados para compreender o impacto e eficiência de políticas de redução da pobreza, proporcionando dados sólidos para uma avaliação bem substanciada.

Para tanto, é necessário formular e selecionar indicadores que sirvam para mensurar informações, que possam monitorar o desenvolvimento da estratégia ao longo do tempo. Parte desse processo envolve determinar os objetivos, os indicadores a serem utilizados e as metas de sua estratégia, a fim de se equacionar um modelo que transpareça claramente o diagnóstico. Os objetivos, aquilo que se quer avaliar, normalmente têm caráter subjetivo e não técnico, como "acabar com a fome" ou "reduzir a pobreza” (PRENNUSHI; RUBIO; SUBBARAO, 2002).

O objetivo deste estudo é discutir e apresentar a aplicação de uma metodologia para desenvolvimento de indicadores para mensurar a performance social de atividades de microfinanças, baseada no enfoque metodológico denominado botton-up. Esse enfoque reflete uma dinâmica participativa e propositiva no sentido de proporcionar o apoderamento dos atores envolvidos em todo o processo de formulação dos indicadores, e contempla, de forma geral, as especificidades existentes nas localidades que se pretende avaliar.

O estudo justifica-se pela importância dos indicadores como ferramenta de planejamento social, econômico e político de governos e entidades do terceiro setor e como instrumento de monitoramento de políticas públicas.

Seguindo-se os pressupostos de Chameret e outros (2007), a metodologia deste artigo é baseada em um estudo de caso, com quatro unidades de análise: atores internos compostos por membros de uma comunidade; ator externo representado por um banco público; atores externos ampliados, que são um laboratório de extensão e uma incubadora tecnológica e, por fim, o agente externo, representado por uma Secretaria de governo.

Como produto do processo de desenvolvimento de indicadores por meio de um enfoque bottom-up, este estudo apresenta, ao final, uma tabela com indicadores que podem ser compreendidos, aceitos e, portanto, considerados legítimos por todos os atores envolvidos na sua adoção.

O artigo estrutura-se da seguinte forma: na segunda seção apresenta-se uma discussão sobre indicadores e microfinanças, na seção três explicase o enfoque bottom-up proposto por Chameret e outros (2007) e discute-se sua aplicação para microfinanças, na quarta seção apresenta-se a aplicação da metodologia, na quinta analisam-se os resultados e na última seção apresentam-se as considerações finais.

\section{INDICADORES E MICROFINANÇAS}

Ao final dos anos 60, diversos organismos internacionais e regionais participaram de esforços para estudar, desenvolver e compreender indicadores sociais. Dentre esses, destacamse a Organização das Nações Unidas (ONU) e seus órgãos especializados, como o ex-Conselho para Assistência Econômica Mútua (COMECON), a União Europeia (ex-Comunidade Econômica Europeia, CEE), a Organização de Cooperação e Desenvolvimento Econômico (OCDE) e o Instituto Interamericano de Estatística (SANTAGADA, 1993).

Em 2005, o Consultative Group to Assist the Poor (CGAP), a Ford Foundation e a Argidius Foundation criaram o Social Performance Task Force (SPTF) com o objetivo de definir "performance social em microfinanças" e analisar questões relativas à mensuração e administração do performance social na provisão de serviços financeiros para a população de baixa renda (FOUNDATION CRIARAM O SOCIAL PERFORMANCE TASK FORCE, 2007).

Antes de aprofundar a análise sobre indicadores de performance social em microfinanças, serão apresentados alguns conceitos sobre indicadores.

Indicadores são as variáveis utilizadas para mensurar o progresso em relação ao objetivo determinado, enquanto metas são os resultados quantitativos dos indicadores propostos, que servem para balizar a avaliação dos objetivos. O quadro 1 ilustra as diferenças.

Quadro 1 - Modelo: objetivos, indicador e meta

\begin{tabular}{|c|l|l|}
\hline Objetivo & \multicolumn{1}{|c|}{ Indicador } & \multicolumn{1}{c|}{ Meta } \\
\hline Reduzir a pobreza & $\begin{array}{l}\text { Número de pessoas que vivem com } \\
\text { menos de \$2/dia }\end{array}$ & $\begin{array}{l}\text { No período de três anos todas as pessoas } \\
\text { tenham uma renda superior a \$2/dia }\end{array}$ \\
\hline
\end{tabular}

Fonte: Deponti e outros (2002). 
Um processo de avaliação se inicia com a definição de um objetivo, ou seja, com a definição do intuito da avaliação, do que se pretende compreender. Um exemplo para o caso das microfinanças é "melhorar a qualidade de vida e acesso ao sistema financeiro" de um determinado grupo de pessoas, ou ainda "inserir mais pessoas no mercado de consumo", dentre outros exemplos.

Os estudos de alguns autores como Cervini e Burger (1985), Sliwiany (1987) e Rocha (2003) apontam que, para a mensuração do bem-estar e qualidade de vida, é fundamental o aprofundamento qualitativo das abordagens realizadas por meio dos indicadores (SANTAGADA, 1993).

A construção de indicadores pressupõe seguir uma metodologia, a qual não deve ser tão rígida a ponto de ser restritiva e nem tão aberta a ponto de ser completamente desestruturada. A metodologia tem a proposta de indicar caminhos que devem delinear a elaboração dos indicadores.

A metodologia proposta para a elaboração dos indicadores deve, necessariamente, preceder, já como uma primeira etapa, uma reunião com o grupo identificado como atores chave do processo ou que de alguma forma serão envolvidos na avaliação e monitoramento do estudo. Na etapa seguinte, é importante que se estabeleça o objeto do estudo, no sentido de se determinar uma delimitação espacial e o caráter da avaliação a ser desenvolvida (DEPONTI et al, 2002).

Para se desenvolver uma metodologia de construção de indicadores é necessário pensar no que se pretende alcançar e, portanto, a forma como se pretende fazer isso. Muitos indicadores são construídos com base no enfoque metodológico denominado top-down, o qual pressupõe uma hierarquia no processo de construção dos indicadores, formados e pensados de forma estritamente institucional, com critérios absolutos, rígidos e genéricos, a fim de possibilitar uma padronização e, portanto, uma comparação entre diferentes sistemas avaliados (CHAMARET; O'CONNOR; RÉCOCHÉ, 2007).

Neste estudo tem-se o objetivo de discutir e apresentar a aplicação de uma metodologia para desenvolvimento de indicadores, baseada no enfoque metodológico denominado botton-up. Esse enfoque reflete uma dinâmica participativa e propositiva no sentido de proporcionar o apoderamento dos atores envolvidos em todo o processo de formulação dos indicadores, e contempla, de forma geral, as especificidades existentes nas localidades que se pretende avaliar. O principal motivo para a adoção do enfoque bottom-up na elaboração dos indicadores propostos neste estudo é que as metodologias concebidas a partir de uma estrutura top-down tendem a falhar na legitimidade de sua avaliação para com os atores chave e na adequação com as questões específicas (CHAMARET; O'CONNOR; RÉCOCHÉ, 2007; GINKEL, 2005).

É importante que os indicadores sirvam para responder às necessidades dos usuários, logo, é importante compreender "quem são os usuários" e "quais são suas necessidades". A metodologia proposta para utilização neste estudo pretende responder essas questões através da aplicação das diversas etapas descritas na próxima seção.

\section{CONSTRUÇÃO DOS INDICADORES PARA MICROFINANÇAS NAABORDAGEM BOTTOM-UP}

A metodologia utilizada neste estudo, para construção dos indicadores, baseia-se nas quatro etapas propostas por Chamaret, O'Connor e Récoché (2007). O estudo desses autores teve como objetivo propor um modelo para mensurar impactos da atividade de mineração sobre o desenvolvimento sustentável. Neste artigo, estamos estendendo a aplicação do modelo para avaliação de impacto de políticas públicas de microfinanças, considerando-o adequado para atingir os objetivos deste estudo.

As etapas do modelo estão representadas na figura 1 e são detalhadas em seguida.

A primeira etapa, de identificação dos atores chave, consiste na identificação das pessoas que participam, influenciam ou são influenciadas de alguma forma pela política implementada. Essas pessoas podem ser classificadas em quatro diferentes níveis: internos, externos, externos ampliados e autoridades coordenadoras.

Figura 1 - As quatro etapas do processo

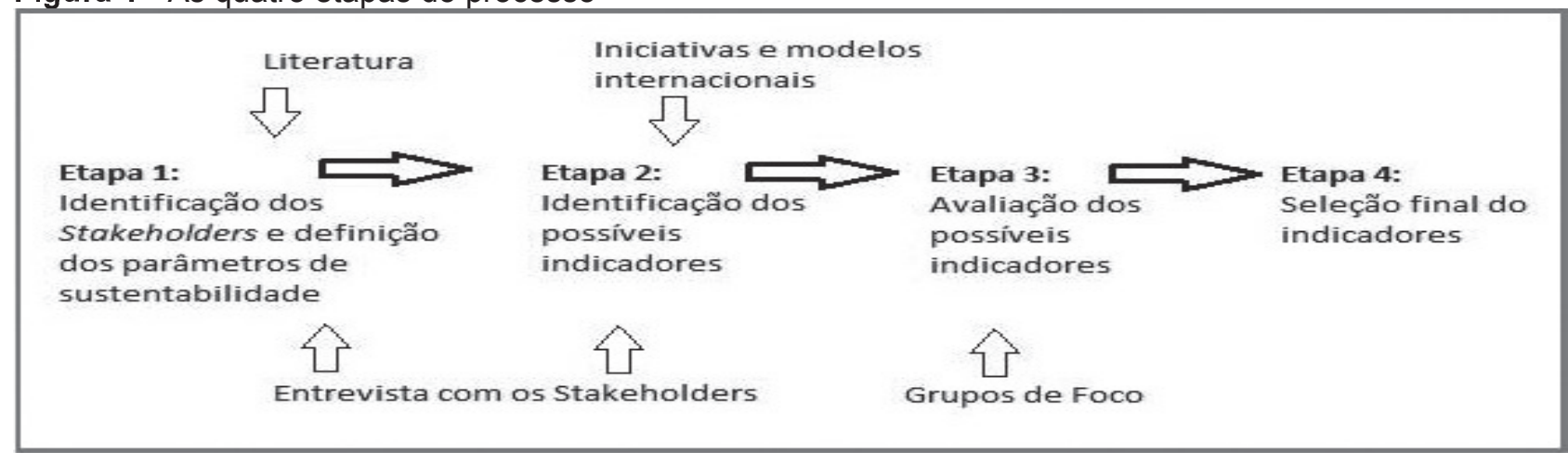

Fonte: Adaptado de Chamaret, O'Connor e Récoché (2007). 
- Os internos são aquelas pessoas que têm interesses diretos, relacionados às ações implementadas. Em se tratando da implementação de uma política pública de microfinanças em uma comunidade, esses atores seriam os membros dessa comunidade.

- Os atores externos são aqueles que estabelecem alguma relação comercial importante com os atores internos. No caso de uma política de microfinanças, os Bancos comerciais seriam esses atores, pois estabelecem uma relação próxima e relevante com os membros das comunidades, implementando ações relacionadas a políticas de microfinanças.

- Os externos ampliados são aqueles que possuem uma relação de parceria com os atores internos, ou algum interesse relacionado aos mesmos. Por exemplo, ONG's e Universidades, que estudam ou trabalham como parceiros na implementação da política de microfinanças.

- As autoridades coordenadoras são as que possuem relação com a política implantada, enquanto agentes externos e indiretos, como governos, fundações ou instituições privadas. No exemplo da política de microfinanças, esses atores podem estar diretamente relacionados aos projetos implementados, mas essa não é uma condição necessária.

$\mathrm{Na}$ segunda etapa da identificação de indicadores, há um processo de coleta de informações, com base em possíveis fontes de indicadores já existentes, como o modelo do Banco Mundial ou do Grammen Bank. A seguir, os indicadores selecionados dessas fontes são sugeridos aos atores-chave. Esses atores aprovam indicadores apresentados e sugerem outros, com base no que consideram como fatores relevantes para avaliação.

Os indicadores podem abordar temas distintos, como impacto no comércio local, aumento da renda dos comerciantes, maior empregabilidade na comunidade, maior facilidade de acesso ao crédito, dentre outros aspectos que forem apontados como relevantes para a dinâmica local.

Após a apresentação do total de possíveis indicadores, os atores- chave devem classificá-los em (1) muito relevante, (2) relevante, (3) pouco relevante e (4) irrelevante, o que deve resultar em uma pré-seleção. Após identificados os possíveis indicadores, é importante que esses sejam classificados em categorias por diferentes áreas, por exemplo, comércio, renda e crédito.

Em seguida, na terceira etapa, é necessário realizar a avaliação de relevância dos indicadores propostos. A dinâmica para essa avaliação se dá através da organização dos atores- chave, divididos em grupos menores para realização de focus group, que, com a presença de um facilitador, devem selecionar no máximo cinco indicadores, de cada categoria de atores-chave (integrantes do comércio, renda e crédito, por exemplo) com os quais todos do grupo concordem. Os grupos são compostos por atores da mesma categoria, para que haja liberdade de se expressarem sem constrangimento e para evitar que haja o risco de existir assimetria de poder, gerada, por exemplo, por discussões entre acadêmicos universitários e comunidade local. Como o intuito é que os indicadores sejam compostos pela diversidade de opiniões, optou-se por utilizar grupos homogêneos internamente e heterogêneos entre si (RABIEE, 2004).

$\mathrm{Na}$ quarta etapa do processo de definição dos indicadores é necessário, por fim, selecionar de fato quais serão os indicadores a utilizar para a avaliação. Para tanto são propostos alguns princípios que devem guiar a seleção:

1. Os indicadores deverão se originar de uma forte medida de consenso.

2. Devem expressar forte interesse da parte dos atores- chave.

3. Devem manter equilíbrio dos interesses dos atores-chave envolvidos.

4. Devem abordar a maior diversidade possível de questões, apontadas nas etapas anteriores.

Para que se tenha maior clareza sobre como selecionar de forma que, de fato, seja contemplada a diversidade e sejam agregadas propostas de consenso, é interessante que seja feita uma análise sobre a importância atribuída pelas diferentes classes de atores- chave a cada um dos itens avaliados durante as etapas. A figura 2 apresenta um exemplo, elaborado a partir da proposta de Chamaret, O'Connor e Récoché (2007).

Ao final da seleção, é importante que haja indicadores de diferentes categorias homogeneamente distribuídos, a fim de que sejam abordados diferentes aspectos relativos ao impacto da política que está sendo avaliada, ao mesmo tempo em que se contemplem as demandas e anseios locais expostos pelos atores-chave.

A metodologia proposta para utilização neste estudo é baseada no fato de que a avaliação do impacto de políticas de microfinanças apresenta uma complexidade de questões que envolvem diversos setores e atores da sociedade, e que somente através de uma abordagem inclusiva e participativa é possível mensurar, de forma qualitativa e quantitativa, essa complexidade de aspectos que impactam as comunidades locais. 
Figura 2 - Avaliação dos atores

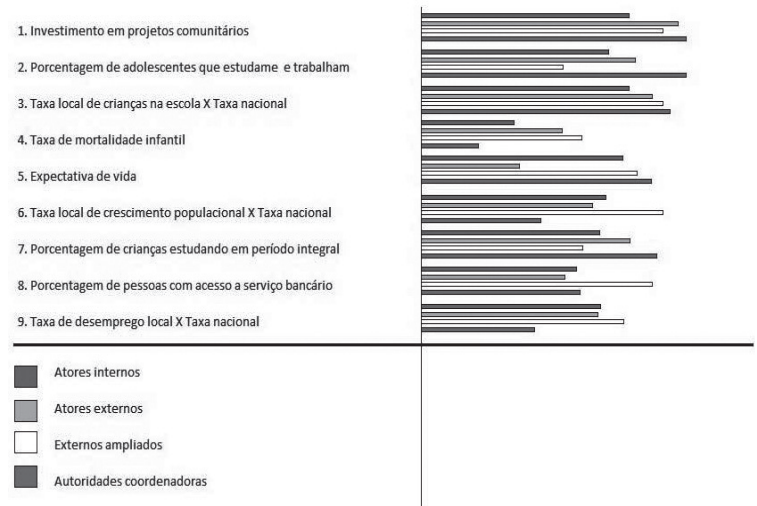

Fonte: Adaptado de Chamaret, O'Connor e Récoché (2007).

Essa abordagem metodológica pretende dialogar com o conceito de microfinanças proposto por Amartya Sen (2000), uma vez que deve servir aos propósitos de avaliação de políticas de microfinanças inclusivas. O autor afirma que a pobreza não deve ser entendida apenas como privação de renda, mas também e principalmente, como a privação de capacidades. $O$ analfabetismo, a doença, a miséria, a falta de acesso ao crédito, aos serviços públicos e à participação social e/ou política, dentre outras, revelamse como "privações de capacidades" cujo obstáculo impede a superação da pobreza (SEN, 2000).

No mesmo sentido Magalhães e Abramovay (2006) sugerem que:

\begin{abstract}
Não ter acesso a mercados é uma das dimensões mais importantes e perversas da desigualdade, pois opera como verdadeiro "bloqueio à entrada" de indivíduos privados das condições básicas que poderiam permitir melhor aproveitamento, pela sociedade, de suas energias e talentos. Mercados financeiros restritos estão associados a limites na valorização do trabalho dos mais pobres e, portanto, contribuem para manter a pobreza.
\end{abstract}

Antes de concluirmos esta seção, é importante apresentar alguns conceitos de microfinanças, para que a proposta de avaliação a partir do modelo de Chemaret et al (2007) possa ser adequadamente contextualizada. Assim, segundo Monzoni (2008, $30)$, microfinanças podem ser compreendidas como:

[...] um conjunto de serviços financeiros (poupança, créditos e seguros), prestados por instituições financeiras ou não, para indivíduos de baixa renda e microempresas (formais e informais) excluídas (ou com acesso restrito) do sistema financeiro tradicional [...]

Robinson (2001) define microfinanças como serviços financeiros de pequena escala, principalmente composto por serviços de crédito e poupança, para pessoas que trabalham em pequenos ou microempreendimentos individuais ou de grupos situados em níveis locais, seja em área urbana ou rural. Esse tipo de serviço visa a ajudar pessoas de baixa renda a reduzir seus riscos, melhorar a gestão, aumentar a produtividade, dentre outros fins, com o objetivo de melhorar sua renda e melhorar a sua qualidade de vida e de sua família ou dependentes (ROBINSON, 2001).

Tais serviços são raramente acessíveis através do sistema financeiro tradicional, dado que as taxas e exigências legais para acessar o sistema não condizem com a realidade que os mais pobres vivem. A definição de microcrédito de Yunus (2000) - um dos serviços oferecidos pelas atividades de microfinanças - vai ao encontro das necessidades dos mais carentes. Segundo o autor, a definição de microcrédito apresenta três variáveis essenciais: é dirigido para os pobres, o valor dos empréstimos é pequeno e inexiste a necessidade de garantias (YUNUS, 2000).

Ganhador do prêmio Nobel da Paz de 2006, o economista Muhammad Yunus descobriu através de suas pesquisas que o maior obstáculo para o desenvolvimento econômico das pessoas mais pobres era a falta de acesso ao crédito (GLENWICK, 2007). Com a perspectiva de romper esse ciclo de pobreza e gerar desenvolvimento social e econômico, por meio de empréstimos financeiros de baixo valor, Yunus fundou o Grameen Bank em 1976. O resultado dessa experiência foi que o modelo de microfinanças adotado conseguiu promover a inclusão financeira de pessoas com baixa renda e estabelecer taxas de adimplência acima de $90 \%$ dos empréstimos concedidos (TODARO; SMITH, 2006).

Hoje, aproximadamente $95 \%$ dos empréstimos realizados pelo Grameen Bank são feitos para mulheres. Como consequência dessas estatísticas "[...] os empregos para mulheres na cidade e no meio rural têm gerado um novo espírito dos direitos das mulheres, além da independência financeira e emponderamento, o que tem feito toda a diferença para essas mulheres." (SACHS, 2005, apud BEILMAN, 2009, p. 1).

No Brasil, apesar de existirem diversas iniciativas de microfinanças, ainda pode-se dizer que é um país que se encontra em um estado de desenvolvimento, com um grande potencial de crescimento, visto que $70 \%$ da população brasileira está excluída do sistema financeiro tradicional, segundo estudo do Banco Nacional de Desenvolvimento Econômico e Social (BNDES).

\section{APLICAÇÃO DA METODOLOGIA}

Com base nos pressupostos acima apresentados, a aplicação da metodologia para a formulação de indicadores de impacto para microfinanças resultou em um quadro de indicadores. 
A estratégia de pesquisa adotada foi o estudo de caso, com quatro unidades de análise (Yin, 2008). O caso é a política de microfinanças no Brasil, com a participação de quatro atores específicos abaixo descritos, que são definidos como distintas, mas integradas unidades de análise.

Para a formulação dos indicadores, foi realizada primeiramente a identificação dos atores envolvidos com a política de microfinanças (as quatro unidades de análise). Para tanto, podem-se compreender como principais atores:

- Banco Comunitário - atores internos. Compreendem a própria comunidade, a qual é agente local do serviço de microfinanças, ao mesmo tempo em que seus membros também são os próprios beneficiados.

- Banco público (ABC) - ator externo. Este tem uma relação direta com a política de microfinanças e com o próprio Banco Comunitário, viabilizando os serviços financeiros a serem executados pela comunidade local por meio do Banco Comunitário.

- Laboratório de Extensão (LABEX) e Incubadora Tecnológica de Cooperativas Populares (ITCP) - atores externos ampliados. Ao mesmo tempo em que possuem uma relação próxima com as comunidades locais, são parte da Universidade de São Paulo, exercendo - papel de parceiros dos Bancos Comunitários.

- Secretaria Nacional de Economia Solidária (SENAES/MTE) - autoridade coordenadora. Secretária do Governo Federal, a qual é responsável por viabilizar e fomentar iniciativas na área de economia solidária, no caso as microfinanças. É um agente externo, que tem um trabalho de representação institucional de forma indireta.

Após a identificação dos atores-chave do processo, foi necessário realizar a coleta de dados e informações sugeridas pelos atores, os quais foram os candidatos a indicadores. Para identificação desses possíveis indicadores, foi necessário utilizar a ferramenta de grupo de foco.

O grupo de foco é uma técnica que busca coletar dados, entender e explicar os significados, crenças e culturas que influenciam os sentimentos, atitudes e comportamento dos indivíduos, por meio de uma interação de grupo baseada em um tópico determinado pelo pesquisador (RABIEE, 2004; MORGAN, 1996). Também, pode-se afirmar que é uma metodologia de pesquisa qualitativa, exploratória semiestruturada, que busca compreender níveis mais profundos da consciência, como crenças e valores (MALHOTRA, 1999).

Os grupos de foco utilizados para a pesquisa foram heterogêneos entre si, já que foram compostos por diferentes atores, mas, internamente, foram homogêneos, pois foram oriundos de um mesmo segmento. Tal modelo foi proposto com base na ideia de que em um grupo de foco os indivíduos devem sentir-se confortáveis, uns com os outros, para que se envolvam na discussão e interação, produzindo assim os dados esperados (RABIEE, 2004). Caso se optasse por colocar os diferentes atores em grupos heterogêneos, possivelmente haveria constrangimento entre as partes, o que poderia comprometer a dinâmica proposta pelo grupo de foco.

Além disso, um importante tema que aparece na literatura dos grupos de foco é a ideia de que essa metodologia tem a habilidade de "dar a voz" aos grupos marginalizados (MORGAN, 1996). No caso desta pesquisa, a metodologia proposta valoriza da mesma forma as comunidades periféricas marginalizadas, público-alvo da política de microfinanças, bem como o interesse de uma organização governamental.

Para este estudo foram realizados quatro grupos de foco, sendo um para cada grupo de atores. Cada dinâmica foi centrada em duas perguntasguia, as quais serviram para conduzir cada dinâmica dentro do tema central, que no caso foi a avaliação de impacto das microfinanças. As perguntas-guia utilizadas com os atores foram as seguintes: 1) "Quais são os impactos e as preocupações relacionadas à política de microfinanças (correspondente bancário ${ }^{1}$ ou banco comunitárioº?)" e 2) "Como vocês mediriam esse impacto?" O objetivo foi o de que os indivíduos do grupo discutissem sobre o tema e as questões apresentadas, enquanto o facilitador observava, conduzia e realizava anotações, que eram consideradas relevantes para o objetivo do estudo.

Com isso, o objetivo foi o de que os atores envolvidos, de forma espontânea, revelassem suas expectativas em relação à política de microfinanças e que assim se pudessem obter indicadores que permitissem mensurar se as microfinanças têm, de fato, atingido seu objetivo.

Durante as discussões entre os participantes da dinâmica, o facilitador realizou anotações relativas aos aspectos relevantes apontados ou possíveis indicadores que estavam sendo gerados e que permitiriam avaliar o impacto da política de microfinanças.

Após a execução dessa dinâmica, os indivíduos do grupo avaliaram, em uma escala de "1" a "5", sendo " 1 " nada relevante e "5" muito relevante, os possíveis indicadores apontados pelo próprio grupo. Essa avaliação resultou nos indicadores escolhidos por aquele grupo de atores- chave, conforme apresentados na próxima seção. 


\section{RESULTADOS}

Na figura 3 são apresentados os resultados obtidos a partir da realização do grupo de foco com o Banco Comunitário, o ator interno.

Figura 3 - Grupo de Foco atores internos: Banco Comunitário (comunidade)

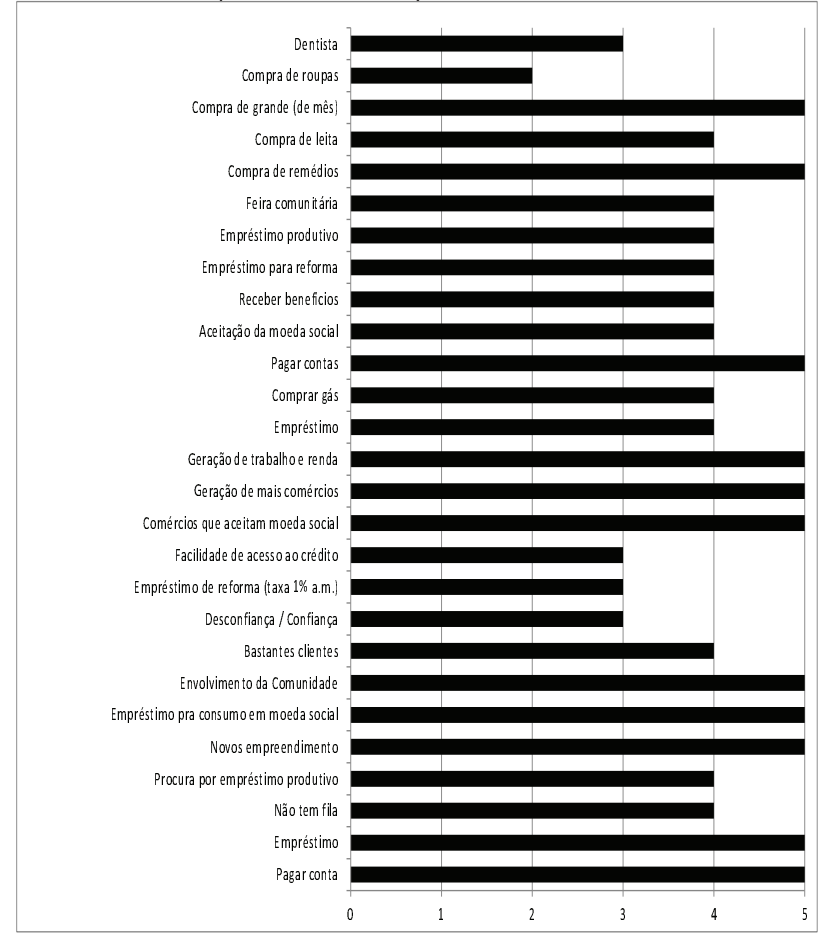

Fonte: Elaboração de seus autores

Foram doze os possíveis indicadores mais bem avaliados no grupo de foco. São eles: "Pagar conta", "Empréstimo", "Procura por empréstimo produtivo", "Empréstimo consumo em moeda social", "bastantes clientes", "Geração de mais comércios", "Geração de Trabalho e Renda", "Não ter fila", "comércios que aceitam moeda social", "Envolvimento da Comunidade", "Compra de Remédios" e "Compra grande (do mês)".

Para melhor análise desses resultados, é possível codificar os dados. A codificação consiste em processo de seleção e transformação dos dados brutos, como das citações feitas durante o grupo de foco, a fim de se identificarem componentes essenciais. Tal processo é feito através da análise das transcrições e localização das informações relevantes, as quais são identificadas como "códigos emergentes" que, inspirados pelo quadro conceitual, são classificados como "códigos preliminares", os quais devem ser classificados em grupos temáticos (LAVOIE, 2010). Os grupos estão ilustrados no Quadro 2.

Esses resultados apontam que existe, principalmente, uma carência de acesso a serviços financeiros e que, para a comunidade local, o objetivo esperado para a política de microfinanças, no caso executada por meio do correspondente bancário e banco comunitário, está diretamente ligada ao acesso aos serviços financeiros.
Quadro 2 - Categorias de Indicadores: grupo de foco atores internos

\begin{tabular}{|l|l|}
\hline \multirow{4}{*}{$\begin{array}{l}\text { Acesso a } \\
\text { serviços finan- } \\
\text { ceiros }\end{array}$} & Pagar conta \\
\cline { 2 - 2 } & Empréstimo \\
\cline { 2 - 2 } & $\begin{array}{l}\text { Empréstimo para consumo em moeda } \\
\text { social }\end{array}$ \\
\cline { 2 - 2 } & Bastantes clientes \\
\hline $\begin{array}{l}\text { Desen- } \\
\text { volvimento } \\
\text { econômico } \\
\text { local }\end{array}$ & Geração de mais comércios \\
\cline { 2 - 2 } $\begin{array}{l}\text { Qualidade de } \\
\text { serviços }\end{array}$ & Geração de Trabalho e Renda \\
\cline { 2 - 2 } & Comércios que aceitam moeda social \\
\cline { 2 - 2 } & Envolvimento da Comunidade \\
\hline \multirow{2}{*}{$\begin{array}{l}\text { Qualidade de } \\
\text { consumo }\end{array}$} & Compra de Remédios \\
\cline { 2 - 2 } & Compra grande (do mês) \\
\hline
\end{tabular}

Fonte: Elaboração de seus autores

Figura 4 - Grupo de Foco Ator Externo: banco público $A B C$

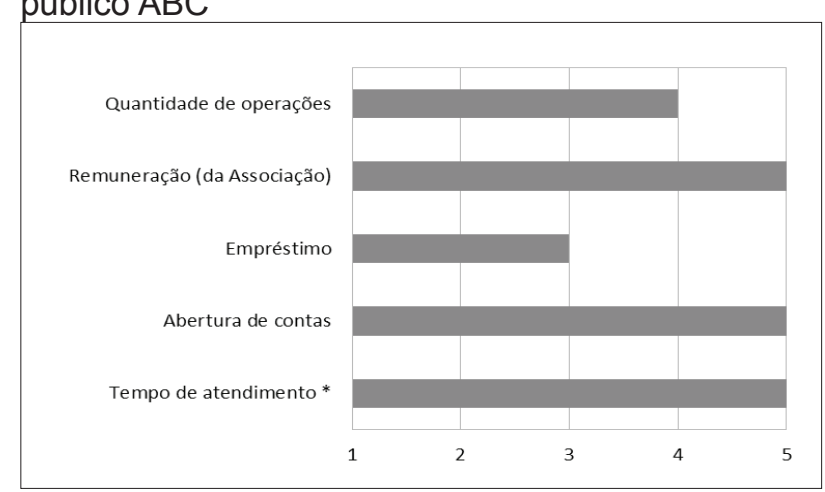

Fonte: Elaboração de seus autores

Em seguida, podem-se observar os resultados obtidos na pesquisa realizada com o ator externo, o Banco público, o qual fornece o suporte institucional para a manutenção e execução dos serviços financeiros oferecidos.

O "tempo de atendimento" é referente ao tempo de atendimento na agência do Banco público, ou seja, se a criação do correspondente bancário reduz o tempo de atendimento na agência. Esse indicador é utilizado para avaliar a eficiência das agências.

Os resultados observados na Figura 4 apontam alguns aspectos interessantes que traduzem 0 ponto de vista do ator externo em relação as suas expectativas quanto aos objetivos a alcançar com os serviços financeiros. Pode-se dizer que este ator tem uma visão mais institucional do serviço, traduzido por indicadores mais quantitativos.

Em seguida, realizou-se o grupo de foco com o ator externo ampliado, um grupo do Laboratório de Extensão da Universidade de São Paulo (campus Leste), composto por pessoas que participaram do projeto de implantação ou que já tiveram contato direto com os Bancos comunitários. 
Diferentemente dos atores anteriores, o grupo externo ampliado possibilitou a coleta de uma gama de possíveis indicadores muito mais amplos, qualitativos e profundos (figura 5). Talvez por ser um grupo pertencente à universidade, a ideia de radicalizar algumas expectativas aparece mais presente, como por exemplo, a expectativa de que os próprios insumos dos produtos consumidos na comunidade tenham sua origem de produção na própria região ou também a ideia de se extinguir a dependência das grandes redes de comércio e dos bancos tradicionais.

Através do método de codificação (LAVOIE, 2010), é possível identificar, dentre os candidatos a indicadores considerados mais relevantes, duas

Figura 5 - Grupo de Foco Atores

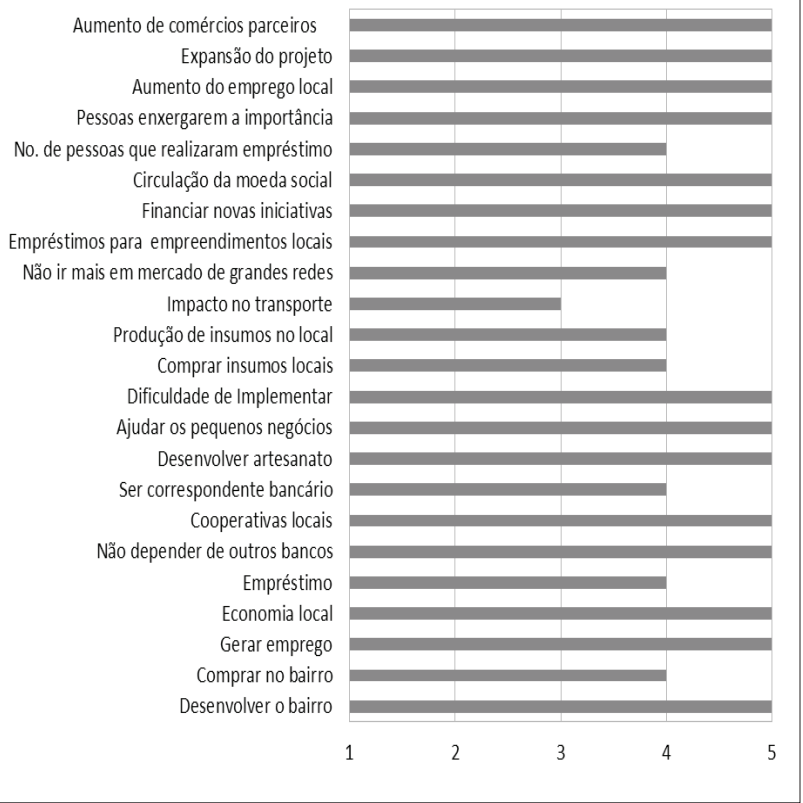

Fonte: Externos Ampliado - Laboratório de Extensão (LABEX).

Figura 6 - Grupo de Foco autoridade coordenadora: Secretaria Nacional de Economia Solidária

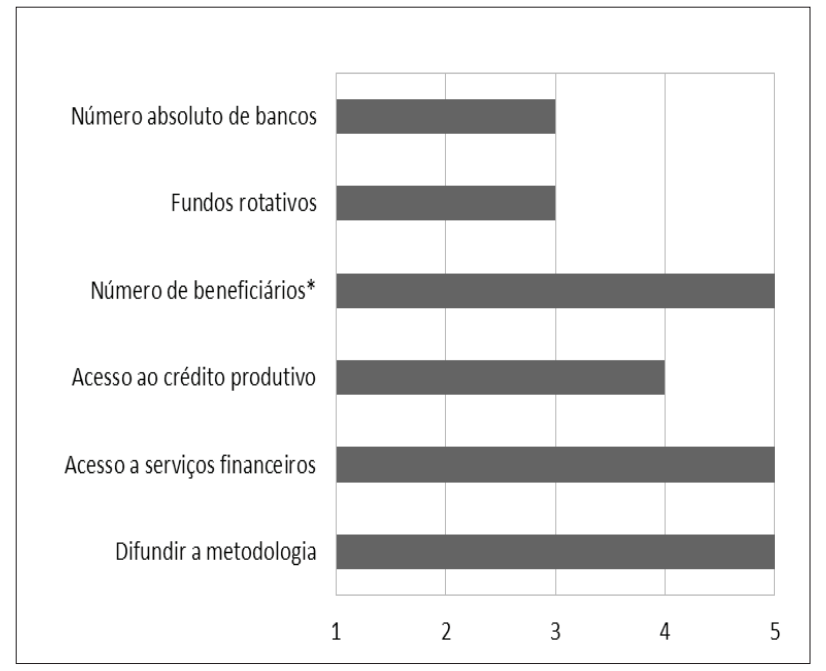

Fonte: Elaboração de seus autores grandes categorias, as quais são "Desenvolvimento econômico local" e "Qualidade de serviços" (Quadro 3).

$\mathrm{Na}$ figura 6 é possível visualizar o resultado obtido a partir do grupo da autoridade coordenadora, representada pela Secretaria Nacional de Economia Solidária (SENAES).

Os resultados apresentam maior avaliação para os indicadores referentes a: "Número de beneficiários", "Acesso a serviços financeiros" e "Difundir a metodologia". Verifica-se que este grupo apresenta preocupações coincidentes com o grupo de atores internos, mas também destaca a preocupação em relação à forma de ampliação dos processos adotados, por meio da difusão da metodologia.

Quadro 3 - Categorias de indicadores: grupo de foco atores externos ampliado

\begin{tabular}{|c|c|}
\hline \multirow{10}{*}{$\begin{array}{l}\text { Desen- } \\
\text { volvimento } \\
\text { Econômico } \\
\text { Local }\end{array}$} & Aumento do emprego local \\
\hline & $\begin{array}{l}\text { Empréstimos para a iniciativas e em- } \\
\text { preendimentos locais }\end{array}$ \\
\hline & Financiar novas iniciativas \\
\hline & Cooperativas locais \\
\hline & Desenvolver artesanato \\
\hline & Ajudar os pequenos negócios \\
\hline & Desenvolver o bairro \\
\hline & Gerar emprego \\
\hline & Economia local \\
\hline & Circulação de moeda social \\
\hline \multirow{5}{*}{$\begin{array}{l}\text { Qualidade } \\
\text { do Serviço }\end{array}$} & Não depender de outros bancos \\
\hline & Dificuldade de implementar \\
\hline & Pessoas enxergarem a importância \\
\hline & $\begin{array}{l}\text { Expansão do projeto (infraestrutura, pro- } \\
\text { jetos parceiros) }\end{array}$ \\
\hline & Aumento de comércios parceiros \\
\hline
\end{tabular}

Fonte: Elaboração de seus autores

Quadro 4 - Quadro final de Indicadores

\begin{tabular}{|c|c|}
\hline \multirow{3}{*}{ Ator Interno } & $\begin{array}{l}\text { Empréstimo para consumo em } \\
\text { moeda social }\end{array}$ \\
\hline & $\begin{array}{l}\text { Comércios que aceitam a moeda } \\
\text { social }\end{array}$ \\
\hline & Compra de remédios \\
\hline \multirow{3}{*}{ Ator Externo } & Remuneração (da Associação) \\
\hline & Abertura de contas \\
\hline & Tempo de atendimento \\
\hline \multirow{3}{*}{$\begin{array}{l}\text { Externo Ampli- } \\
\text { ado }\end{array}$} & Aumento do emprego local \\
\hline & Cooperativas locais \\
\hline & Pessoas enxergarem a importância \\
\hline \multirow{3}{*}{$\begin{array}{l}\text { Autoridade Co- } \\
\text { ordenadora }\end{array}$} & Número de beneficiários \\
\hline & $\begin{array}{l}\text { Acesso a serviços financeiros } \\
\text { (crédito, poupança e seguro) }\end{array}$ \\
\hline & Difusão da metodologia \\
\hline
\end{tabular}

Fonte: Elaboração de seus autores 
A partir desses resultados, agregando os candidatos a indicadores mais bem avaliados de cada segmento de atores, foi possível construir uma lista de indicadores de impacto para a política de microfinanças estudada, a qual contempla os interesses e expectativas dos diferentes grupos.

No quadro 4 é possível observar o resultado da aplicação da metodologia bottom-up proposta para a formulação de indicadores de impacto para microfinanças. A tabela apresenta a seleção, a fim de contemplar a maior diversidade de questões apontadas, de três indicadores propostos e melhor avaliados por cada um dos grupos participantes da dinâmica.

\section{CONCLUSÃO}

O resultado obtido por meio da metodologia proposta apresenta uma gama de indicadores que contempla as expectativas de todos os atores envolvidos na política de microfinanças, segundo as teorias estudadas. Como pode ser observado, foram apresentados tanto indicadores qualitativos - como "Pessoas enxergarem a importância" e "Difusão da metodologia", como indicadores quantitativos - como "Comércios que aceitam moeda social" e "Remuneração (da Associação)", dentre outros.

Com isso, a proposta deste artigo, de discutir e apresentar a aplicação de uma metodologia para formulação de indicadores que pudesse interpretar de forma real as expectativas dos atores envolvidos na política de microfinanças e avaliar seu impacto foi cumprida. A forma como a metodologia foi aplicada confirmou que para que se obtenham indicadores que sejam relevantes para os atores envolvidos, é fundamental construí-los com a sua participação. A relevância desses indicadores é percebida na legitimidade que os atores atribuem aos mesmos, capazes de permitir a avaliação de aspectos críticos, segundo seus olhares e perspectivas.

A abordagem adotada mostrou-se capaz de dialogar com as expectativas dos atores envolvidos, muitas dessas relacionadas às necessidades de avaliar e reduzir as privações de capacidades e não somente as privações de renda. As privações de capacidades, como falta de acesso aos serviços financeiros, revelaram-se entre os principais aspectos relevantes para o grupo de atores internos, composto por membros da comunidade. Por outro lado, o ator externo revelou interesse na eficiência do sistema já existente. Essas expectativas podem coincidir com as expectativas dos atores internos, uma vez que maior eficiência pode contribuir para qualidade e para maior acesso da população aos serviços financeiros já existentes.

No entanto, é necessário ressaltar que as expectativas dos atores externos (banco público) não necessariamente contribuem para atender as demandas da população. Uma das maiores carências hoje é a ampliação da gama de serviços financeiros oferecidos, ainda bastante restritos aos serviços de recebimento de contas. Segundo o Banco Central do Brasil (2010), ainda existe dificuldade para a massificação do microcrédito no Brasil, principalmente o microcrédito produtivo orientado, que pode contribuir para maior geração de renda nas comunidades.

$\mathrm{Na}$ análise dos resultados apresentados pelo grupo externo ampliado, composto por membros da universidade que trabalham em conjunto com a comunidade, verifica-se uma vasta gama de indicadores, revelados com base não somente no que os membros das comunidades percebem como suas necessidades imediatas, mas também com base em conhecimentos acadêmicos que Ihes permitem elaborar uma análise mais ampla, que não necessariamente é a mais conectada com as necessidades locais, mas que contribui para enriquecer o debate.

A autoridade coordenadora mostra-se preocupada com aspectos que coincidem com as expectativas dos atores internos (membros da comunidade) e, ao mesmo tempo, com aspectos relevantes para disseminar os processos já existentes, como a "difusão da metodologia" que de alguma maneira está relacionada à preocupação do grupo externo ampliado de promover formas para que "pessoas enxerguem a importância" do acesso aos serviços financeiros.

As coincidências ou diferenças de expectativas entre os grupos estudados revelam um interessante material de análise que merece ser ampliado a partir de novos estudos, multiplicados em outros grupos que compartilhem as preocupações relativas ao acesso aos serviços microfinanceiros e suas consequências para o desenvolvimento econômico e social.

\section{REFERÊNCIAS}

BANCO CENTRAL DO BRASIL. Panorama de acesso a serviços financeiros. IN: Relatório de Inclusão Financeira. Brasília, DF, 2010. p. 4769. Disponível em: <http://www.bcb.gov.br/Nor/ relincfin/relatorio_inclusao_financeira.pdf>. Acesso em: 03 fev. 2012.

BEILMAN, Michael. Microfinances in Rural Ecuador: a case study of la cooperativa de ahorro y crédito desarrollo de los pueblos CODESARROLLO Ltda.12. Journal of Undergraduate Research, Wisconsin, v. 12, 2009

SACHS, Jeffrey. The end of poverty: economic possibilities for our time. New York: Penguin Books, 2005.

CHAMARET, Aurélie; O'CONNOR, Martin; RÉCOCHÉ, Gilles. Top-down/Bottom-up approach for developing sustaintable development indicators for mining: application to the arlit uranium mines (Niger). International Journal Sustaintable Development, Versailles, v. 10, n. 1/2, p. 161-174, 2007. 
COSTA, Tereza Cristina Nascimento A. Considerações teóricas sobre o conceito de indicador social: uma proposta de trabalho. Revista Brasileira de Estatística, Rio de Janeiro, v. 36, n. 142, p. 167-176, abr./jun. 1975.

DEPONTI, Cidonea Machado et al. Estratégia para construção de indicadores para avaliação da sustentabilidade e monitoramento de sistemas. Agroecologia e Desenvolvimento Rural Sustentável, Porto Alegre, v. 3, n. 4, p. 44-52, out./ dez. 2002.

DINIZ, Henrique Eduardo. Correspondentes bancários e microcrédito no Brasil: tecnologia bancária e ampliação dos serviços financeiros para a população de baixa renda. Relatório de Pesquisa FGV/EAESP/GVPesquisa, 2007.

GINKEL, Rob Van. Between top-down and bottomup governance: Dutch beam trawl fishermen's engagement with fisheries management. In: Tim S. Gray (Ed.). Participation in fisheries Governance Netherlands: springer, 2005. p. 119-139.

GLENWICK, Michael. Is Microcredit the answer or an answer for Latin America? [S.I.], 2007. Disponível em: <http://www.coha.org/>. Acesso em: 20 abr. 2012

LAVOIE, Frédéric. Understanding the transferability and local appropriation of microcredit methodologies. In: . Partial fulfilment of requirements for the degree of Master of Science. Montréal: HEC, 2010.

MAGALHÃES, Reginaldo; ABRAMOVAY, Ricardo. Acesso, uso e sustentabilidade do PRONAF $B$. São Paulo: MDA/FIPE, 2006.

MALHOTRA, Neresh. Pesquisa de Marketing. São Paulo: Bookman, 1999.

MONZONI, Mario. Impacto em renda do microcrédito. São Paulo: Peirópolis, 2008.

MORGAN, David. Focus group. Annual Review of Sociology, Palo Alto, CA, v. 22, p. 129-152. 1996.

PRENNUSHI, Giovanna; RUBIO, Gloria; SUBBARAO, Kalanidhi. Monitoring and evaluation. Poverty Reduction Strategies Paper Sourcebook, Washington, DC, 2002.

RABIEE, Fatemeh. Focus-group interview and data analysis. Proceedings of the Nutrition Society, Birmingham, UK, v. 63, p. 655-660, nov. 2004.

RATTNER, Henrique. Indicadores sociais e planificação do desenvolvimento. Revista de Administração de Empresas, Rio de Janeiro, v. 17, n. 1, p. 21-27, jan./fev. 1977.

ROCHA, Sonia. Pobreza no Brasil: afinal, de que se trata? Rio de Janeiro: FGV, 2003.
ROBINSON, Marguerite. The microfinance revolution. Washington, DC: The World Bank and Open Society Institute, 2001.

SANTAGADA, Salvatore. Indicadores sociais: contexto social e breve histórico. Indicadores Econômicos FEE, Rio Grande do Sul, v. 20, n. 4, 1993

SEGUNDO, Joaquim Melo. Bancos comunitários. Le Monde Diplomatique Brasil, São Paulo, p. 2425, jan. 2009.

SEN, Amartya. Desenvolvimento como liberdade. São Paulo: Companhia das Letras, 2000.

SOCIAL PERFORMANCE TASK FORCE. Declaration of principles. [S.I.], 2007.Disponível em:

<http://sptf.info/page/background-1>. Acesso em: 15 jan. 2012

TODARO, Michael; SMITH, Stephen. Economic development. 9. ed. Boston: Addison-Wesley, 2006.

YUNUS, M. O banqueiro dos pobres. São Paulo: Ática, 2000.

Notas

Correspondente Bancário: O conceito de correspondente bancário refere-se a um acordo entre duas instituições, uma dos quais (o correspondente) aceita depósitos e presta serviços em nome de outra (o respondente) (DINIZ, 2007). Por meio de um correspondente bancário, um imigrante residindo no Canadá, nos EUA ou no Japão, por exemplo, envia recursos para a sua família no seu país de origem.

2 Banco Comunitário: "Bancos comunitários são serviços financeiros solidários, em rede, de natureza associativa e comunitária, voltados para a geração de trabalho e renda na perspectiva de reorganização das economias locais, tendo por base os princípios da Economia Solidária. Seu objetivo é promover o desenvolvimento de territórios de baixa renda, através do fomento à criação de redes locais de produção e consumo... (SEGUNDO, 2009)".

Tania P. Christopoulos

Administradora

Doutorado em Administração de Empresas pela Fundação Getúlio Vargas de São Paulo

Professora da Universidade de São Paulo (USP)

E-mail: tchristo@usp.br

Tomás C. A. Marques

Pesquisador

Universidade de São Paulo (USP)

E-mail: tomarques182@usp.br

Universidade de São Paulo (USP)

Cidade Universitária, São Paulo - SP

CEP: 05508-900. Cidade 